\title{
Las dificultades del espíritu crítico-científico en una sociedad autoritaria
}

\author{
H. C. F. Mansilla | Academia de Ciencias de Bolivia
}

\section{Resumen:}

El área andina de América Latina ha experimentado tres grandes corrientes histórico-culturales que han contribuido a moldear la mentalidad colectiva: (1) el legado civilizatorio precolombino, (2) la tradición iberocatólica, y (3) la recepción instrumentalista de la modernidad occidental. Las dos primeras fomentaron una cultura autoritaria y colectivista, poco favorable al espíritu crítico-científico. La restauración de la democracia (a partir de 1980) fomenta, con muchos obstáculos, una universalización de los derechos humanos y la introducción de un espíritu abierto a la investigación científica seria. Estos esfuerzos han mitigado la fuerza del autoritarismo y han debilitado las certezas dogmáticas.

Palabras clave: autoritarismo, colectivismo, cultura precolombina, tradición ibero-católica, democratización.

\section{Abstract:}

The Andean area of Latin America has experienced three main historical and cultural currents, which had a strong influence on collective mentality: (1) the pre-Hispanic Indian civilizations, (2) the Iberian-Catholic tradition, and (3) a mere instrumental reception of actual western modernity. Both first influences furthered an authoritarian and collectivistic culture and were not favourable to a critical and scientific spirit. The reestablishment of democracy since 1980 promotes (with many impediments) a generalization of human rights and the introduction of a mentality opened to serious scientific research. These efforts have softened the power of authoritarianism and weakened the dogmatic attitudes.

Key words: authoritarianism, collectivism, pre-Hispanic culture, Iberian-Catholic tradition, democratization.

Q in entrar a un debate teórico --siempre insatisfactorio--; sobre definiciones conceptuales y problemas afines, se pueden hacer algunas aseveraciones de índole provisoria en torno a los complejos nexos entre el espíritu crítico-científico y una sociedad con rasgos autoritarios. Las afirmaciones siguientes están pensadas para el área andina de América Latina, sobre todo para la región comprendida entre Ecuador y Bolivia [1]. Aunque las generalizaciones en ciencias sociales resultan siempre precarias e inexactas, son, por otra parte, indispensables si se quiere decir algo que tenga relevancia teórica y sea algo más que una mera reproducción de la realidad 
empírica. Esto es tanto más necesario cuanto faltan estudios serios y bien documentados sobre los vínculos entre la actividad que habitualmente llamamos científica y las mentalidades que han prevalecido y que aun son dominantes en la zona andina [2] .

Durante el último medio siglo todos los países andinos han experimentado notables procesos de modernización, que han generado una marcada especialización de roles y funciones, una intensa diferenciación de los tejidos sociales y una expansión sin precedentes de los estratos medios. Algunos de los aspectos más importantes de este proceso son las múltiples modificaciones acaecidas en la esfera de aquello que imprecisamente llamamos la cultura popular. El fenómeno más importante y curioso es, empero, la pervivencia de mentalidades premodernas en medio del proceso de modernización acelerada. El término premoderno alude aquí a actitudes autoritarias, prerracionales, convencional-conservadoras y tradicionalistas, las cuales persisten paralelamente a la adopción de normativas occidentales modernas en la esfera económica, la administración pública y el ámbito académico.

En la región andina la situación del espíritu crítico-científico puede ser mejor comprendida si consideramos brevemente las tres grandes corrientes históricoculturales que han contribuido a moldear la mentalidad colectiva: (1) el legado civilizatorio precolombino, (2) la tradición ibero-católica, y (3) la recepción instrumentalista de la modernidad occidental.

\section{El legado civilizatorio prehispánico y su pervivencia en el ámbito indígena}

No hay duda de los notables logros del Imperio Inca (y de las culturas que lo antecedieron) en muchos terrenos de la actividad humana, logros que se extienden desde la arquitectura y la infraestructura de comunicaciones hasta prácticas de solidaridad inmediata y un sentimiento estable de seguridad, certidumbre e identidad lo cual no es poco, ciertamente. La dignidad superior atribuida a lo supra-individual fomentó valores de orientación y modelos organizativos de índole colectivista. Los padrones ejemplares de comportamiento social eran la predisposición a la abnegación y el sacrificio, la confianza en las autoridades y el sometimiento de los individuos bajo los requerimientos del Estado [3] . Todo esto condujo a una actitud básica que percibía en la institución gubernamental algo natural y bienvenido y que consideraba todo cambio social y político como algo negativo e incómodo. 
Las civilizaciones precolombinas no conocieron ningún sistema para diluir el centralismo político, para atenuar gobiernos despóticos o para representar en forma permanente e institucionalizada los intereses de los diversos grupos sociales y de las minorías étnicas. La homogeneidad era su principio rector, como puede detectarse parcialmente aun hoy en el seno de las comunidades campesino-indígenas. Esta constelación histórico-cultural no ha fomentado en estas latitudes el surgimiento de pautas normativas de comportamiento y de instituciones gubernamentales que resultasen a la larga favorables al individuo como persona autónoma, a los derechos humanos como los concebimos hoy, a una pluralidad de intereses y opiniones que compitiesen entre sí y, por consiguiente, al florecimiento de un espíritu críticocientífico.

Las comunidades indígenas se hallan hoy inmersas en un proceso de modernización, y es verosímil que esto último haya sido inducido por factores exógenos, como el contacto diario con el mundo moderno y la influencia de la escuela y de los medios masivos de comunicación [4] . Paralelamente a este decurso modernizante las culturas indígenas del presente conservan a menudo rasgos autoritarios en la estructuración social, en la mentalidad colectiva y también en la vida cotidiana y familiar. Estos fenómenos no concitan el interés de los partidos indigenistas y de sus intelectuales, quienes más bien fomentan una autovisión de los aborígenes basada en un panorama idealizado y falso del pasado: las culturas precolombinas habrían sido profundamente democráticas y no habrían conocido relaciones de explotación y subordinación [5] . En resumen para el ámbito andino: la civilización incaica debería ser vista como un socialismo revolucionario y original, pero en estadio embrionario [6] . Es precisamente esta concepción la que dificulta la difusión de un espíritu crítico-científico: promueve una visión complaciente y embellecida de la propia historia, atribuye todas las carencias del pasado y de la actualidad a los agentes foráneos y evita un cuestionamiento del comportamiento, la mentalidad y los valores de orientación del propio pueblo. En este campo las corrientes izquierdistas y nacionalistas no han significado una ganancia cognoscitiva de la comunidad respectiva y más bien han contribuido a menudo a consolidar los aspectos autoritarios en el mundo indígena.

También hoy entre cientistas sociales existen tabúes, aun después del colapso del socialismo. Así como antes entre marxistas era una blasfemia impronunciable achacar 
al proletariado algún rasgo negativo, hoy sigue siendo un hecho difícil de aceptar que sean precisamente los pueblos indígenas y los estratos sociales explotados a lo largo de siglos - y por esto presuntos depositarios de una ética superior y encargados de hacer avanzar la historia - los que encarnan algunas cualidades poco propicias con respecto a la cultura cívica moderna, a la vigencia de los derechos humanos y al despliegue de una actitud básicamente crítica.

No hay duda de que casi todos los grupos poblacionales indígenas intentan adoptar lenta pero seguramente numerosos rasgos básicos del mundo occidental, sobre todo en los campos de la técnica y la economía. Como este designio tiene lugar, al mismo tiempo, con el redescubrimiento de sus valores ancestrales, lo que finalmente emerge es una compleja y contradictoria amalgama que tiene una relevancia decisiva para la configuración de las identidades colectivas del presente [7]. Esta problemática se halla inmersa en el debate mayor entre valores particularistas y coerciones universalistas [8], por un lado, y en la discusión sobre la identidad colectiva [9], por otro. En los países andinos se puede constatar una controversia tácita entre la conservación de la tradicionalidad aborigen y los intentos de alcanzar la modernidad a la brevedad posible, controversia no explícita que tiene lugar en el seno de cadacomunidad indígena $\mathrm{y}$, en realidad, en la consciencia de muchos individuos. Esta pugna es particularmente clara y de intensidad mayor en grupos indígenas de urbanización reciente y formación universitaria. Además hay que consignar que numerosas reivindicaciones indígenas encubren conflictos muy habituales por la posesión de recursos naturales cada vez más escasos, como tierras agrícolas y fuentes de agua [10] . Nada de esto es sorprendente, pues pertenece al acervo de la historia universal [11] . Actualmente se puede aseverar que en la región andina se dan dos fenómenos al mismo tiempo. Por un lado el proceso de modernización, por más modesto que sea, ha socavado en forma lenta pero segura la autoridad, el prestigio y las funciones que eran inherentes a las colectividades indígenas definidas según criterios étnico-culturales. La mayor autoconsciencia individual, la construcción de la personalidad de acuerdo a parámetros urbanos, racionales y universales y las imágenes omnipotentes de la globalización cultural contribuyen a debilitar todo nexo identificatorio tradicional. Por otro lado, la misma acción modernizadora provoca una fuerte reacción defensiva de las comunidades aborígenes, que intentan preservar sus valores y normas y el control sobre sus miembros precisamente con más ahínco cuando se saben amenazadas de muerte, a menudo revitalizando tradiciones autoritarias [12] . 
En la actualidad las tendencias indigenistas e indianistas [13] hacen evidente un cierto fundamentalismo sobre todo en el anhelo de reconstruir lo propio diferenciándose de lo ajeno, lo extranjero, moderno y occidental; y en el rechazo del "imperialismo cultural" de Europa y los Estados Unidos, rechazo que engloba creaciones civilizatorias de índole universalista como el espíritu crítico-científico, los derechos humanos y ciudadanos, algunas pautas contemporáneas de comportamiento socio-político (como la democracia representativa liberal) y algunos valores actuales de orientación (por ejemplo el individualismo y la tolerancia pluralista). Esta inclinación fundamentalista, aunque atenuada, impide el autocuestionamiento de la propia constelación, de sus valores de orientación y de sus metas históricas, lo que constituye, en el fondo, el factor más importante de una actitud crítica.

Por otra parte, este intento de recrear un modelo civilizatorio propio puede ser calificado de traumatizante y de inútil: los ingredientes aparentemente más sólidos y los factores más sagrados del acervo cultural e histórico del actual espacio andino resultan ser una mixtura deleznable y contingente de elementos que provienen que otras tradiciones nacionales o que tienen una procedencia común con los más diversos procesos civilizatorios [14] . La quintaesencia identificatoria nacional o grupal, estimada como algo primordial, básico e inalterable, sólo puede ser definida y comprendida con respecto a lo complejo, múltiple y cambiante que está encarnado en lo Otro, es decir en los elementos determinantes de las culturas ajenas y hasta hostiles. Este ejercicio de la búsqueda por lo auténtico y propio tiene efectos traumáticos porque pone de relieve el hecho de que el núcleo cultural que puede ser considerado

efectivamente como la identidad nacional incontaminada constituye un fenómeno de importancia y extensión decrecientes. La inmensa mayoría de los estados existentes actualmente no poseía una consciencia nacional hace escasamente doscientos años [15] . El despertar político de la población indígena en toda el área andina puede estar justificado en términos sociales e históricos, pero conlleva el peligro de un renacimiento del autoritarismo colectivista, lo que no es favorable a un espíritu crítico [16] .

\section{La tradición ibero-católica y su influencia actual}

No hay duda de que la larga era colonial española y luego la republicana, que continuó algunos elementos centrales de la explotación y subordinación de los indígenas, han 
generado en las etnias aborígenes una consciencia muy dilatada de nación oprimida, de una injusticia secular no resuelta y de agravios materiales y simbólicos aun vivos en la memoria popular. Estas tendencias no formulan soluciones practicables, pero sí han fomentado un imaginario colectivo altamente emocional, que simultáneamente se cierra al análisis racional y al debate realista de su condición actual. La exacerbación de elementos comunitaristas y particularistas debilita los aspectos razonables de la modernidad, como la democracia pluralista, el Estado de Derecho, la concepción de los derechos humanos y la moral universalista.

La mentalidad prevaleciente en el área andina no puede ser disociada del relativo estancamiento histórico que sufrieron España y Portugal a partir del siglo XVI. Este atraso evolutivo no puede ser desvinculado del conocido talante iliberal y acrítico que permeó durante largo tiempo las sociedades ibéricas, el que fue responsable parcialmente por la esterilidad de sus actividades filosóficas y científicas, por la propagación de una cultura política del autoritarismo y por la falta de elementos innovadores en el terreno de la organización social. Se pueden aducir varios argumentos contra estas aseveraciones, como su carácter generalizante, el tratamiento poco diferenciado de unos fenómenos históricos altamente complejos y el dejar de lado el erasmismo español [17] , la ensayística política española de los siglos XVII y XVIII y los aportes originales de la Ilustración en la península ibérica. Pero lo determinante es que estos factores histórico-culturales no tuvieron ninguna influencia digna de mención en el área andina, la que tampoco experimentó la notable modernización española a partir de las últimas décadas del siglo XIX.

En la región andina se expandió una forma particularmente dogmática y retrógrada del legado cultural ibero-católico, que se destacó por su espíritu irracional, autoritario, burocrático y provinciano. A causa del llamado Patronato Real, establecido en 1508 por una bula papal, la Corona castellana y luego el Estado español ejercieron una tuición severa y rígida sobre todas las actividades de la Iglesia Católica en el Nuevo Mundo [18] . La Iglesia resultó ser una institución intelectualmente mediocre, que irradió pocos impulsos creativos en los ámbitos de la teología, la filosofía y el pensamiento social. Durante la colonia el clero gozó de un alto prestigio social; la Iglesia promocionó un extraordinario florecimiento de las artes, especialmente de la arquitectura, la pintura y la escultura. La Iglesia respetó de modo irreprochable el modus vivendi con la Corona y el Estado; toleró sabiamente rituales y creencias sincretistas; y sus tribunales 
inquisitoriales procedieron, en contra de lo que ocurría en España, con una tibieza encomiable. Pero esta Iglesia no produjo ningún movimiento cismático; le faltaron la experiencia del disenso interno y la enriquecedora controversia teórica en torno a las últimas certidumbres dogmáticas. Debido a la enorme influencia que tuvo la Iglesia en los campos de la instrucción, la vida universitaria y la cultura en general, todo esto significó un obstáculo insuperable para el nacimiento de un espíritu científico.

Las naciones ibéricas no estimularon ni contribuyeron esencialmente al nacimiento del mundo moderno, basado en el desarrollo impetuoso de la ciencia y la tecnología, en la industrialización y la regulación metódica de la vida cotidiana. Al sur de los Pirineos y en el ámbito colonial español y portugués no se dio hasta el siglo XIX una comprensión adecuada de los cimientos espirituales y cognoscitivos de los procesos modernizadores y tampoco, paradójicamente, una actitud crítica con respecto a lo negativo de la modernidad. Cuando las naciones latinoamericanas y especialmente las andinas ingresaron al arduo camino de la modernización, lo hicieron copiando indiscriminadamente los modelos ya existentes, ofreciendo muy poca resistencia a los aspectos antihumanos contenidos en aquellos sistemas imitativos de modernización, los cuales predominan aun hoy en la fase contemporánea de la evolución latinoamericana.

Algunos males del presente (baste el referirse a las prácticas cotidianas del Poder Judicial, de la administración pública y de la universidad) tienen que vercasi directamente con aquella tradición socio-histórica. La época colonial conllevó en la región andina una marcada propensión al centralismo [19] , una clara inclinación al estatismo y al burocratismo [20] y un cierto desprecio por labores intelectuales y creativas. La atmósfera de las universidades de esa época era similar a la prevaleciente en las Altas Escuelas de la Edad Media: no existía la inclinación a relativizar y cuestionar las certidumbres dogmáticas y los conocimientos considerados como verdaderos. Predominaba en cambio una enseñanza de naturaleza receptiva, basada en la memorización de textos y en la formación de destrezas retóricas. La investigación científica y las capacidades crítico-analíticas no fueron desarrolladas. Los debates podían ser intensos, pero acerca de cuestiones triviales [21]. Varias de estas características han persistido hasta hoy; los intelectuales adscritos al sistema universitario han sido - con pocas y notables excepciones - buenos receptores e intérpretes de ideas foráneas, pero no autores de planteamientos novedosos y 
heurísticos a escala mundial.

Todos estos factores han sido importantes para la conformación de la cultura política del autoritarismo, que durante siglos determinó el ambiente cultural de América Latina y de la región andina. Pero no se trata de esencias indelebles y perennes de una presunta identidad colectiva que es inmune al paso del tiempo, a transformaciones internas y a las influencias foráneas. Son fenómenos históricos, es decir: transitorios y pasajeros, pero que durante ciertos periodos, que pueden ser muy largos, determinan la atmósfera cultural e intelectual de un territorio. Los esfuerzos por implantar la democracia, el Estado de Derecho y el pluralismo ideológico en el área andina a partir de 1980 han mitigado la fuerza del autoritarismo y han debilitado las certezas dogmáticas; hoy en día se da, por lo tanto, la esperanza de que el espíritu críticocientífico pueda aclimatarse adecuadamente en América Latina y en la zona andina [22] .

\section{La recepción instrumentalista de la modernidad occidental}

Las sociedades del área andina tienden a adoptar la modernidad occidental en cuanto la proliferación de espacios sometidos a la racionalidad de los medios, como se manifiesta de modo patente en la acogida extremadamente favorable que le ha sido deparada a la tecnología en todas sus manifestaciones. Los avances técnicos son percibidos en la zona andina como hechos de validez universal, dignos de ser incorporados inmediatamente a las actividades productivas, distributivas y organizativas del país respectivo. Esta concepción en torno al carácter únicamente positivo de la tecnología contrasta con la opinión muy difundida entre nacionalistas, izquierdistas e indigenistas de que la filosofía del racionalismo, el espíritu críticocientífico, el genuino individualismo, el respeto inviolable a los derechos de la persona, el pluralismo ideológico y la libertad de expresión, serían productos secundarios y fortuitos, circunscritos a un ámbito geográfico y temporal restringido (la Europa Occidental de los siglos XVI al XIX) y, por lo tanto, de una validez relativa. Fenómenos de vigencia parcial no merecen, obviamente, que se les preste una atención demasiado intensa y menos aún que sean integrados dentro de los valores de orientación de la vida cotidiana y de los parámetros de la planificación del desarrollo.

En el área andina está difundida la idea tácita de que es posible y deseable separar un invento técnico de su contexto científico de origen. La importación masiva de tecnologías 
ha dejado de lado el sustrato científico, el espíritu crítico e indagatorio que hicieron posible la ciencia $\mathrm{y}$, por consiguiente, el florecimiento técnico-industrial contemporáneo. La apropiación incesante de tecnologías civiles y militares, consideradas como productos "neutrales" de la inventiva humana y, por lo tanto, como libres de las peligrosas inclinaciones occidentales en favor de actitudes indagatorias y probatorias, sirve para tender un velo sobre la posible intención socio-política que subyace a numerosos intentos de modernización acelerada: la preservación de estructuras premodernas de tinte marcadamente antidemocrático, iliberal y antipluralista.

En tierras andinas el resultado es una modernidad de segunda clase: hay enormes ciudades que poseen todos los inconvenientes y pocas de las ventajas de las grandes urbes del Norte; la urbanización apresurada y la apertura de vastos territorios suceden sin una preocupación colectiva por la contaminación ambiental y la destrucción de la naturaleza; la construcción de instituciones cívicas y políticas ha ocurrido hasta cerca de 1980 prescindiendo de los designios de liberalidad, democracia, tolerancia y pluralismo que animaron los orígenes de aquéllas en el marco de la civilización occidental.

Las grandes creaciones del Occidente europeo han pasado al Nuevo Mundo por un tamiz de economicismo, pragmatismo e instrumentalismo, dando como efecto una recepción acrítica, unilateral y parcialmente deformada de la modernidad. Estas aseveraciones se entienden como limitadas al campo de su aplicación práctica y no conciernen obviamente los afanes de eruditos, literatos y artistas. El sesgo utilitarista y tecnocrático que ha tomado la modernidad en el área andina viene a ser mucho más pronunciado que en sus sociedades metropolitanas de origen y se manifiesta en la cultura popular y en el destino experimentado por las universidades.

\section{Lo rescatable de las tradiciones y los dilemas actuales}

Esta crítica de las tradiciones socio-culturales del área andina es a todas luces insuficiente, ya que deja de lado los aspectos positivos - es decir, válidos hasta hoy de aquellas herencias históricas. En lo referente al legado ibero-católico hay que considerar los rasgos razonables que pueden ser localizados en la configuración de la vida cotidiana, en las estructuras familiares, en los ritmos laborales, en el ornato y la estética públicas, en el mayor respeto por los ecosistemas naturales y en el 
reconocimiento de las limitaciones inherentes a la especie humana, lo cual ha estado ligado a sentimientos religiosos. Aunque nos encontramos con un tema altamente complejo, cuyo tratamiento diferenciado puede despertar la impresión de un argumento esquizofrénico, es indispensable ver estas tradiciones desde una perspectiva adicional para percibir, aunque sea someramente, sus elementos rescatables y provechosos.

Por ejemplo: la tradición ibero-católica ha conocido también normativas y comportamientos, a los que ahora se les atribuye el carácter de lo anticuado y depasado por el rumbo pretendidamente inevitable del progreso material e histórico, los que, sin embargo, han simbolizado y encarnan todavía hoy - en la literatura y en la memoria colectiva de muchos pueblos de la región - diversos fragmentos aun válidos de una vida más plena y humana y de un convivencia más sana que los principios comparables derivados de la cultura de la modernidad. La herencia ibero-católica implicaba una relación distanciada, escéptica y hasta ingeniosa con respecto a la administración pública y al Estado: contenía además una ética laboral que no exaltaba el trabajo metódico y continuado ni el ascetismo intramundano a la categoría de fin óptimo de la especie humana y actitud gratísima ante los ojos de Dios - como lo hace todavía la mayoría de las confesiones protestantes.

Estos aspectos de la tradición ibero-católica no juegan, empero, un rol importante en la cultura practicada actualmente. El punto de referencia para la élite burocrática del poder, para los responsables de configurar la opinión pública y para la mayor parte de las clases medias no es la cultura indígena ni la herencia ibero-católica, sino las normas y los valores encarnados en la cultura globalizada de las naciones del Norte [23] . Todos estos segmentos sociales han sufrido un proceso más o menos largo de asimilación y aculturación, tomando como propios los padrones de orientación de la civilización norteamericana del presente y considerándolos como parámetros obligatorios de la evolución histórica universal. Al mismo tiempo, la consciencia colectiva en los países andinos intenta renovar su legado socio-cultural y contraponerlo al modelo irradiado desde los centros metropolitanos, pero con un resultado mediocre. Las culturas andinas se hallan a la defensiva dentro del universo del desarrollo científico-tecnológico de proveniencia metropolitana. Pero esta resistencia es mayoritariamente retórica y de poca influencia real en la praxis cotidiana. 


\section{Conclusiones provisionales}

El carácter imitativo del desarrollo andino actual debe ser visto en conjunción con la mencionada recepción unilateral de importantes fragmentos del pensamiento occidental. Se ha adaptado como genuinamente autóctono el precepto occidental de que los designios humanos son factibles si hay la firme voluntad política de implementarlos. Al mismo tiempo se difunde la concepción judeo-cristiana en torno a la desacralización de la naturaleza: el cosmos deja de ser un objeto de contemplación y admiración (con valiosas connotaciones estéticas, religiosas y morales) y se transforma en el mero substrato de recursos que puede y debe ser aprovechado hasta el último resquicio sin consideraciones ecológicas o conservacionistas. La consecuencia global [24] es un ordenamiento económico, político y cultural con rasgos claros de imitación subalterna, carente de originalidad en las esferas decisivas de la vida moderna, especialmente en el campo de la economía, la tecnología y la organización empresarial e institucional, $\mathrm{y}$, a causa de su falta de racionalidad a largo plazo, con el peligro de socavar su propio fundamento natural si persiste el ritmo actual de destrucción del medio ambiente y del crecimiento demográfico.

La adopción de los paradigmas metropolitanos de desenvolvimiento socio-económico y de pautas de consumo de proveniencia occidental ha sido facilitada enormemente por las mejoras en el campo de las comunicaciones, por el incremento de los contactos personales entre individuos de la civilización industrial y de los países andinos y por la ampliación de las oportunidades de educación superior. Las aspiraciones colectivas cada vez más altas en lo que concierne al nivel de vida, al consumo y a las distracciones conforman el fenómeno moderno de la revolución de las expectativas crecientes, que puede ser también definido como el anhelo colectivo de obtener lo más pronto posible los frutos de las sociedades altamente desarrolladas del Norte, frutos que desde el interior de los países andinos son vistos como reivindicaciones justas, deseables y obvias por casi todas las corrientes de opinión del espectro político-ideológico. Por la ausencia de una tradición cultural verdaderamente crítica, la consciencia colectiva está abierta y simultáneamente sometida a los llamados efectos de demostración de un modo de vida supuestamente superior. El impacto de estos efectos ha sido singularmente fuerte entre los intelectuales, las élites políticas y empresariales y los estratos medios, y ha conducido a que la actividad primordial de estos grupos esté 
centrada en torno a los conceptos mágicos de progreso y desarrollo. Los resultados avasalladores de los efectos de demostración sobre la consciencia colectiva representan, en el fondo, efectos de fascinación [25], ya que los modelos metropolitanos tienden a ser internalizados como básicamente propios e históricamente justificados.

Importantes sectores de la opinión pública en el área andina anhelan que la consecución de progreso y desarrollo englobe los valores metropolitanos de orientación colectiva - modernización y urbanización aceleradas, consumo masivo, tecnificación de la vida cotidiana- juntamente con la preservación de la cultura política tradicional y de pautas premodernas de comportamiento en las esferas familiar y cultural. Esta mixtura es al mismo tiempo favorable para perpetuar prácticas irracionales y autoritarias en nombre de una herencia cultural genuinamente propia y bajo el barniz de un designio progresista de desarrollo. La fatal combinación de tecnofilia ingenua y autoritarismo práctico parece ser una posibilidad bastante expandida de evolución histórica, no sólo en América Latina, sino en dilatadas zonas del Tercer Mundo. En los países andinos el futuro del espíritu crítico permanece entonces como precario e impredecible.

[1] Sabine Kurtenbach et al., Die Andenregion - Neuer Krisenbogen in Lateinamerika, Frankfurt, Vervuert 2004

[2] Cf. los volúmenes siguientes, que contienen textos sobre la cultura política en la zona andina: Jorge Nieto Montesinos (comp.), Sociedades multiculturales y democracias en América Latina, México, UNICEF 1999; Arturo Escobar et al. (comps.), Política cultural, cultura política. Una nueva mirada sobre los movimientos sociales latinoamericanos, Bogotá, Taurus 2001.

[3] Cf. Magnus Mörner, The Andean Past: Lands, Societies and Conflicts, New York: Columbia U. P. 1985.- Esta cultura política del autoritarismo no ha tenido significación para las etnias tupi-guaraníes de Sudamérica, que se han destacado por una actitud anti-estatista. Cf. la obra clásica: Pierre Clastres, La société contre l'état. Recherches d'anthropologie politique, París, Minuit 1974. 
[4] Cf. José Antonio Lucero (comp.), Beyond the Lost Decade: Indigenous Movements and the Transformation of Democracy and Development in Latin America, Princeton, Princeton U. P. 2001

[5] Guillermo Bonfil Batalla (comp.), Utopía y revolución. El pensamiento político contemporáneo de los indios en América Latina, México, Nueva Imagen 1981, passim.

[6] Uno de los mejores trabajos sobre esta problemática ha pasado totalmente desapercibido: Manuel Sarkisyanz, Vom Indigenismus als Mythos vom Indianer und indianischer Vergangenheit, en: Manuel Sarkisyanz (comp.), Vom Beben in den Anden. Propheten des indianischen Aufbruchs in Peru, Munich, Dianus-Trikont 1985, pp. ixxxiii.

[7] Helga von Kügelgen (comp.), Herencias indígenas, tradiciones europeas y la mirada europea, Madrid / Frankfurt: Iberoamericana / Vervuert 2002

[8] Cf. el ensayo fundamental: Giacomo Marramao, Paradojas del universalismo, en: SOCIEDAD (Buenos Aires), № 4, mayo de 1994, pp. 25-38

[9] Cf. Nelly Arenas, Globalización e identidad latinoamericana, en: NUEVA SOCIEDAD (Caracas), № 147, enero-febrero de 1997, pp. 121-131; Jorge Larraín Ibáñez, Modernización, razón e identidad en América Latina, Santiago de Chile: Andrés Bello 1996; Daniel Innerarity, ¿Quiénes somos nosotros? Preliminares para una política de la identidad, en: REVISTA DE ESTUDIOS POLITICOS (Madrid), № 113, julioseptiembre de 2001, pp. 225-236.

[10] Sobre los nexos entre las luchas étnico-culturales y la pugna por recursos naturales (especialmente tierra y territorio) a nivel mundial, cf. el número monográfico de INTERNATIONALE POLITIK UND GESELLSCHAFT (Bonn), № 2, abril-junio de 2003

[11] Cf. paralelismos con el mundo islámico: Bassam Tibi, Vom Gottesreich zum Nationalstaat. Islam und panarabischer Nationalismus, Frankfurt: Suhrkamp 1987, p. 30 sqq.; Tibi, Der Islam und das Problem der kulturellen Bewältigung sozialen Wandels, Frankfurt, Suhrkamp 1985, p. 157 sq., 161.

[12] Cf. Berthold Weig, Die vergessenen Völker Lateinamerikas. Indigene Bevölkerung zwischen Neo-Romantizismus und politischem Extremismus, en: KAS- 
AUSLANDSINFORMATIONEN (Berlin), vol. 21, № 1, enero de 2005, pp. 4-12; Ulrich Goedeking, Über Sichtbarkeit und Diversität, en: ibid., pp. 118-130.

[13] Sobre la diferencia entre indianismo (tendencia de los propios indios a la autonomía política e independencia cultural) e indigenismo (corriente proveniente de fuera de los indios y favorable a la mejora de los mismos mediante la aculturación y la imitación de modelos foráneos), cf. José Alcina Franch, El indianismo de Fray Bartolomé de Las Casas, en: Alcina Franch (comp.), Indianismo e indigenismo en América, Madrid, Alianza 1990, p. 38.

[14] Sobre los muchos aspectos del indigenismo, su intento de revitalizar el pasado (una utopía arcaizante), sus frutos literarios y sus magras perspectivas actuales, cf. el hermoso libro de Mario Vargas Llosa, La utopía arcaica. José María Arguedas y las ficciones del indigenismo, México, FCE 1996; cf. también Eduardo Devés Valdés, El pensamiento indigenista en América Latina 1915-1930, en: UNIVERSUM. REVISTA DE LA UNIVERSIDAD DE TALCA, vol. 12, 1997, pp. 37-56.

[15] Sobre las ficciones que fundan y sustentan los nacionalismos cf. el interesante ensayo de Holm-Detlev Köhler, El nacionalismo: un pasado ambiguo y un futuro sangriento, en: REVISTA DE ESTUDIOS POLITICOS (Madrid), № 98, octubre/diciembre de 1997, pp. 172-175; William Pfaff, La ira de las naciones, Santiago de Chile, Andrés Bello 1994

[16] Cf. entre otros: Manfred Rabeneick, Indigene Interessenorganisation und Armutsbekämpfung in Ekuador, en: KAS-AUSLANDSINFORMATIONEN (Berlin), vol. 21, № 1, enero de 2005, pp. 13-29; Angela Meentzen, Indígena und Politik im Andenraum: Peru, en: ibid., pp. 30-56; Stefan Jost, Indigener Protest in Bolivien. Ziele einer radikalisierten Indígena-Bewegung, en: ibid., pp. 57-78.

[17] Cf. Marcel Bataillon, Erasmo y España, México, FCE 1966; José Luis Abellán, El erasmismo español, Madrid, Espejo 1976.

[18] Cf. entre otros: Horst Pietschmann, Staat und staatliche Entwicklung am Beginn der spanischen Kolonisation Amerikas (El Estado y el desarrollo estatal al comienzo de la colonización española en América), Münster, Görres 1980; J. Lloyd Mecham, Church and State in Latin America: A History of Politico-Ecclesiastical 
Relations, Chapel Hill, North Carolina U. P. 1966; Frederick C. Turner, Catholicism and Political Development in Latin America, Chapel Hill, North Carolina U. P. 1971.

[19] Cf. la brillante obra de Claudio Véliz, The Centralist Tradition of Latin America, Princeton, Princeton U. P. 1980.- Para una visión diferente cf. Colin M. MacLachlan, Spain's Empire in the New World. The Role of Ideas in Institutional and Social Change, Berkeley etc., California U. P. 1988; Richard M. Morse, El espejo de Próspero. Un estudio de la dialéctica del Nuevo Mundo, México, Siglo XXI 1982.

[20] Cf. Howard J. Wiarda, Politics and Social Change in Latin America. The Distinct Tradition, Amherst, Massachusetts U. P. 1982; Mario Góngora, Studies in the Colonial History of Spanish America, Cambridge U. P. 1975.

[21] Manfred Mols, Demokratie in Lateinamerika, Suttgart, Kohlhammer 1985, pp. 61,114 .

[22] Para el caso boliviano cf. Carlos Toranzo Roca et al., Democracia y cultura política en Bolivia, La Paz: Corte Nacional Electoral / PRONAGOB 2001; Roberto Laserna, La democracia en el ch'enko, La Paz, Milenio 2004.

[23] Con referencia al mundo islámico Bassam Tibi acuñó la expresión: "disposición hacia una permanente esquizofrenia", para denotar esta tendencia sociopolítica. No hay dudas de que existen notables paralelismos entre el ámbito musulmán y el área andina. Cf. Bassam Tibi, Internationale Politik und EntwicklungsländerForschung, Frankfurt, Suhrkamp 1979, p. 181; cf. también la importante obra de Samuel Kodjo, Probleme der Akkulturation in Afrika (Problemas de la aculturación en Africa), Meisenheim: Hain 1973, cuyo autor presentó un interesante marco teórico para la comprensión de fenómenos actuales de aculturación en el Tercer Mundo. Una de las obras más importantes sobre esta temática es la de Bassam Tibi, Die Krise des modernen Islams. Eine vorindustrielle Kultur im wissenschaftlich-technischen Zeitalter, Munich, Beck 1981.- Estas obras, pioneras en su campo, no han perdido vigencia.

[24] Sobre las ambigüedades de la globalización cf. los estudios críticos: Aníbal Quijano, Colonialidad del poder, globalización y democracia, en: TRAYECTORIAS. REVISTA DE CIENCIAS SOCIALES (Monterrey), vol. 4, № 7/8, septiembre de 2001 / abril de 2002, pp. 58-90; Ulrich Beck, Was ist Globalisierung? Frankfurt, Suhrkamp 
2002; Fernando Mires, Teoría del nuevo capitalismo o el discurso de la globalización, Caracas, Nueva Sociedad 2000.

[25] Cf. la obra que no ha perdido vigencia: Torcuato S. Di Tella, Populism and Reform in Latin America, en: Claudio Véliz (comp), Obstacles to Change in Latin America, Londres etc., Oxford U. P. 1965, p. 48. 